\title{
Women are underrepresented on the editorial boards of journals in environmental biology and natural resource management
}

Despite women earning similar numbers of graduate degrees as men in STEM disciplines, they are underrepresented in upper level positions in both academia and industry. Editorial board memberships are an important example of such positions; membership is both a professional honor in recognition of achievement and an opportunity for professional advancement. We surveyed 10 highly regarded journals in environmental biology, natural resource management, and plant sciences to quantify the number of women on their editorial boards and in positions of editorial leadership (i.e., Associate Editors and Editors-in-Chief) from 1985-2013. We found that during this time period only $16 \%$ of editorial board members were women, with more pronounced disparities in positions of editorial leadership. Although the trend was towards improvement over time, there was surprising variation between journals, including those with similar disciplinary foci. While demographic changes in academia may reduce these disparities over time, we argue journals should proactively strive for gender parity on their editorial boards. This will both increase the number of women afforded the opportunities and benefits that accompany board membership and increase the number of role models and potential mentors for early-career scientists and students. 
1 Women are underrepresented on the editorial boards of journals in environmental biology

2 and natural resource management

3

4 Alyssa H. Cho ${ }^{1}$, Shelly A. Johnson ${ }^{2}$, Carrie E. Schuman ${ }^{3}$, Jennifer M. Adler ${ }^{3}$, Oscar Gonzalez ${ }^{3}$,

5 Sarah J. Graves ${ }^{2}$, Jana R. Huebner ${ }^{3}$, D. Blaine Marchant ${ }^{4}$, Sami W. Rifai ${ }^{2}$, Irina Skinner ${ }^{5}$, and

6 Emilio M. Bruna ${ }^{6,5 *}$

7

$8 \quad{ }^{1}$ Agronomy Department, University of Florida, Gainesville, FL

$9 \quad{ }^{2}$ School of Forest Resources and Conservation, University of Florida, Gainesville, FL

$10 \quad{ }^{3}$ School of Natural Resources and Environment, University of Florida, Gainesville, FL

$11{ }^{4}$ Biology Department, University of Florida, Gainesville, FL

$12{ }^{5}$ Department of Wildlife Ecology \& Conservation, University of Florida, Gainesville, FL

$13{ }^{6}$ Center for Latin American Studies, University of Florida, Gainesville, FL

15 *Corresponding author: Emilio M. Bruna, University of Florida, Center for Latin American

16 Studies and Department of Wildlife Ecology \& Conservation, PO Box 110430, Gainesville, FL,

17 (352) 846-0634, embruna@ufl.edu 


\section{ABSTRACT}

20 Despite women earning similar numbers of graduate degrees as men in STEM disciplines, they

21 are underrepresented in upper level positions in both academia and industry. Editorial board

22 memberships are an important example of such positions; membership is both a professional

23 honor in recognition of achievement and an opportunity for professional advancement. We

24 surveyed 10 highly regarded journals in environmental biology, natural resource management,

25 and plant sciences to quantify the number of women on their editorial boards and in positions of

26 editorial leadership (i.e., Associate Editors and Editors-in-Chief) from 1985-2013. We found that

27 during this time period only $16 \%$ of editorial board members were women, with more

28 pronounced disparities in positions of editorial leadership. Although the trend was towards

29 improvement over time, there was surprising variation between journals, including those with

30 similar disciplinary foci. While demographic changes in academia may reduce these disparities

31 over time, we argue journals should proactively strive for gender parity on their editorial boards.

32 This will both increase the number of women afforded the opportunities and benefits that

33 accompany board membership and increase the number of role models and potential mentors for

34 early-career scientists and students. 
Cho et al., p.3

\section{INTRODUCTION}

37 Despite women in the United States and Europe earning similar numbers of graduate

38 degrees as men do, they remain underrepresented in upper level positions in both academia and

39 industry in these regions (European Commission 2012; National Science Foundation 2004;

40 National Science Foundation 2012). Several mechanisms have been put forward to explain this

41 disparity, including biases against women in hiring, promotion, and offers of compensation, the

42 emphasis on productivity, journal placement, and citation rates as determinants of merit despite

43 evidence of gender bias influencing all three, inflexible or even hostile work environments, and a

44 lack of role models and mentors (reviewed in Budden et al. 2008; Lariviere et al. 2013; Leahey

45 2007; Long 2001; Moss-Racusin et al. 2012). In response, universities, funding agencies, and

46 other institutions have implemented strategies to address these issues, including making

47 opportunities for professional advancement more broadly available and actively seeking gender

48 diversity in leadership roles (Fox 2008). While these efforts have had some positive results,

49 much remains to be done to ensure women in Science, Technology, Engineering, and Math

50 (STEM) disciplines are afforded the same opportunities as their male counterparts.

51 The editorial boards of scientific journals act as gatekeepers that help maintain the

52 scientific integrity and standards of a journal as well as identify emerging and innovative areas of

53 research (Addis \& Villa 2003; Mauleon et al. 2013). An invitation to serve as a Subject Editor is

54 recognition that a scholar is respected in his or her discipline; it is also the path towards

55 leadership positions because Associate Editors and Editors-in-Chief are typically selected from

56 the Subject Editors. Serving on a board is also a means of advancing one's scholarship, both by

57 becoming aware of the latest advances in the field and gaining insights into the writing and 
58 publication process. Finally, editorial boards are important professional networks - in serving on

59 a board one is able to develop relationships with reviewers, authors, and other editors (Addis \&

60 Villa 2003; Pearson et al. 2006). Serving on a board is therefore both an honor and a means of

61 furthering one's research and career.

Previous studies have quantified the gender composition of editorial boards in the social

63 sciences (Addis \& Villa 2003; Green 1998; Stark et al. 1997), business administration and

64 management (Metz \& Harzing 2012), and STEM fields such as information systems (Cabanac

65 2012) and medicine (Galley \& Colvin 2013; Keiser, Utzinger \& Singer 2003; Wilkes \& Kravitz

66 1995). To our knowledge, however, no such efforts have been made in ecology, natural resource

67 management, plant sciences, or related disciplines (collectively referred to here as

68 "environmental biology"). We therefore used ten highly regarded journals in environmental

69 biology to address the following questions: 1) What proportion of editorial board members were

70 women between 1985-2013? 2) How did the representation of women on editorial boards

71 change over this time period? 3) How many women served in leadership positions, i.e., as

72 Editors-in-Chief or Associate Editors?

\section{METHODS}

We selected for review 10 high profile environmental biology journals: Annual Review of

77 Fisheries Management, American Journal of Botany, Conservation Biology, Biological

78 Conservation, Ecology, Journal of Ecology, and Journal of Tropical Ecology. We chose these

79 journals because they are published by the primary professional organizations of which we (i.e.,

80 the authors) are members (e.g., Biotropica, Conservation Biology) or are alternative, non-society 
81 outlets for similar research (e.g., Journal of Tropical Ecology, Biological Conservation). It was

82 not intended to be a random sample of journals or a subset of journals with similar impact

83 factors. Rather, they were chosen because they are the journals many graduate students in

84 environmental biology, natural resource management, and plant sciences, including the authors, 85 target to publish some of their thesis research.

86 Our analyses were based on the years 1985-2013. We chose 1985 as a starting point

87 because it is shortly after studies began demonstrating disparities in career advancement between 88 male and female scientists (reviewed in Long 2001; National Science Foundation 2003) but a

89 few years prior to major initiatives by the US National Science Foundation and others to rectify

90 these disparities (e.g., the 2001 initiation of the ADVANCE Program, National Science

91 Foundation 2014). As such, we expect our survey period to reflect potential shifts in editorial

92 board composition resulting from increased awareness of gender biases in STEM and the results

93 of efforts to rectify these biases. For each journal we selected the first issue published each year

94 and recorded the names, institutions, and editorial positions of all editorial board members. We

95 then used Internet searches, personal knowledge, and interviews of colleagues to determine the

96 gender of each editorial board member. Because of library licensing issues were unable to obtain

97 data for Journal of Tropical Ecology for the years 1986-1989.

98 Journals often have different names for positions with similar editorial responsibilities,

99 these names frequently change over time, and editorial positions are frequently created or

100 eliminated. We therefore assigned editorial board members to the following categories based on

101 their responsibilities: (1) Editor-in-Chief (EIC). The EIC oversees the journal and is ultimately

102 responsible for editorial policy, standards, and practice, including appointing members of the

103 Editorial Board. Some journals (e.g., North American Journal of Fisheries Management) had co- 
104 Editors-in-Chief; in such cases all were included in the total EIC count. (2) Associate Editors

105 (AE). The AE assists the EIC with their responsibilities and may take the lead on some aspects of 106 journal administration; in some cases they might oversee all submissions in a particular subject 107 area or from a geographic region. Not all journals have AEs, while those that do may vary in the 108 length of time they have had them. (3) Subject Editors (SE). The SEs, also commonly referred to 109 as Handling Editors, oversee the process of manuscript review. For some journals they make 110 final decisions on manuscripts after considering reviewer feedback (e.g., Ecology) while for 111 others they provide recommendations based on which EICs or AEs make final decisions (e.g., 112 Biotropica). They also provide formal or informal feedback to the EICs/AEs on journal policy 113 and administration. They are referred to collectively by a variety of titles, including Board of 114 Editors (Ecology, Biological Conservation) and the Editorial Committee (Annual Review of 115 Ecology, Evolution, and Systematic, American Journal of Botany). Note that two journals - the 116 American Journal of Botany and North American Journal of Fisheries Management - used the 117 title of "Associate Editor" for members of their Editorial Board with the responsibilities of SEs; 118 we therefore included them in this category in our analyses. (4) Special Editors. Many journals 119 have someone tasked with organizing special sections, reviewing data archives, soliciting 120 reviews of recently published books of interest to the journal's readers, etc. (e.g., Biological 121 Florida Editors for the Journal of Ecology; Concept Section, Data Archive, Special Features, and 122 Invited Papers Editors for Ecology).

123 We conducted our analyses using only EICs, AEs, and SEs, and throughout our 124 manuscript and analyses we use the term 'Editorial Board' to refer to the group collectively 125 made up of these three categories. Special Editors were not included in our analyses unless they 126 were also identified as EICs, AEs, or SEs because very few journals had these positions and they 
127 rarely existed for the entire survey period. We also excluded from our analyses production staff

128 (e.g., production editors, managing editors, editorial assistants) and the American Journal of

129 Botany's "Section Representatives", which were only present in our survey in 1985 and whose

130 primary function was to help identify journal priorities and suggest reviewers if asked - they did

131 not make editorial decisions on individual manuscripts (Dr. Judith E. Skog, pers. comm., 2014).

\section{RESULTS \& DISCUSSION}

We found that from 1985-2013 only 16\% of editorial board members were women $(\mathrm{N}=$ 332 of 2065, Fig. 1A). The disparity also extends to leadership positions: since 1985 only $14 \%$ of Associate Editors ( $\mathrm{N}=18$ of 125, Fig. 1B) and 12\% of the Editors-in-Chief of our focal journals were women $(\mathrm{N}=7$ of 59, Fig. 1C). Not surprisingly, the proportions of male and female editors were significantly different for all of groups of Editors (proportion tests with continuity corrections, null probability $=0.5, \mathrm{SE}: \chi^{2}=946.44, \mathrm{df}=1, \mathrm{p}<0.0001 ; \mathrm{AE}: \chi^{2}=61.952, \mathrm{df}=1$, $\mathrm{p}<0.0001 ;$ EIC: $\left.\chi^{2}=32.81, \mathrm{df}=1, \mathrm{p}<0.0001\right)$.

While there was a general increase in the representation of women on editorial boards over time, for most journals the percentage of women on the board rarely exceeded 20\% (Fig. 2).

143 Nevertheless, there was notable variation among journals in the representation of gender on their 144 editorial boards during the time period surveyed. For several journals, the proportion of women 145 editors increased from zero in the mid-1980's to 40\% by 2013 (e.g., Biotropica, American 146 Journal of Botany, Conservation Biology). Others, however, had consistently few women on 147 their boards throughout the period surveyed (e.g., Agronomy Journal, North American Journal of 148 Fisheries Management, Biological Conservation). A similar pattern of underrepresentation was 149 observed for Associate Editors and Editors-in-Chief. While most journals had female Associate 
150 Editors at some point during the period surveyed, only 5 of the 10 journals we reviewed had ever

151 had a woman as Editor-in-Chief (Fig. 3). Of these, only one - the North American Journal of

152 Fisheries Management - had multiple women serve as EICs.

153 We recognize that determining the extent of gender bias in the composition of editorial

154 boards in environmental biology will require evaluating many more journals from multiple

155 subfields. However, the results of similar surveys in fields ranging from economics to

156 anthropology have found disparities comparable to those we document (Addis \& Villa 2003;

157 Cabanac 2012; Galley \& Colvin 2013; Green 1998; Keiser, Utzinger \& Singer 2003; Metz \&

158 Harzing 2012). Assuming the results for the journals we reviewed are representative of others in

159 environmental biology, our observations suggest two questions to be addressed by this scientific

160 community. First, why are women underrepresented on editorial boards and in positions of

161 editorial leadership? Second, for what gender composition on editorial boards should journals

162 strive?

While our study was not designed to elucidate why women are underrepresented on

164 editorial boards, potential mechanisms include many of the same ones invoked to explain why

165 women are lacking in leadership positions in other spheres of academia (Fox 2008; Long 2001).

166 It may also be that men continue to be more visible and hence more likely to be identified as

167 potential board members because they have greater productivity, have more first- or last-authors

168 of papers (West et al. 2013), and tend to be “citation elites" (sensu Parker, Allesina \& Lortie

169 2013; Parker, Lortie \& Allesina 2010). It may be that using these metrics to screen for editors

170 might eventually - albeit slowly - result in increased numbers of women on editorial boards.

171 This is because gender-based disparities in rates of publication (West et al. 2013) and citation

172 (Borsuk et al. 2009) are diminishing (but see Lariviere et al. 2013), although this does not appear 
173 to be the case for all disciplines (West et al. 2013). More difficult to overcome might be the

174 reliance on using the social and research networks of (mostly male) editorial board members to

175 identify potential new editors (Addis \& Villa 2003), since women scientists are frequently

176 excluded from such networks or on their periphery (Fox 2008). This is where proactive

177 measures, including the promotion of women to positions of editorial leadership, may have the

178 greatest impact (Galley \& Colvin 2013). Indeed, at least one study has found that having a

179 female Editor-in-Chief is correlated with a greater proportion of women on editorial boards

180 (Mauleon et al. 2013).

181 For what gender composition on editorial boards should journals in environmental

182 biology strive? We propose they should proactively seek gender parity, rather than simply mirror

183 the proportion of women earning doctoral degrees in a specialization, conducting research in

184 particular disciplines, or who are members of academic societies - numbers which, in contrast to

185 other fields (e.g., Morton \& Sonnad 2007), we were surprised to find are extremely difficult to

186 ascertain for environmental biology. Some might argue that the relatively lower number of

187 female senior scholars in certain fields (e.g., agronomy) might make parity a challenge.

188 However, it is important to emphasize that the issue in not whether there is parity in the number

189 of women earning PhDs, but whether there are sufficient qualified women worldwide to

190 comprise half an editorial board, which is a much smaller number (mean number of board

191 members in $2012=56 \pm 41.3 \mathrm{SD}$, range $=9-127)$. It is difficult to argue that there are not, given

192 the global reach of academic societies (Carroll 2014), the internationalization of research

193 programs (Stocks et al. 2008), increases in research productivity in developing countries

194 (Holmgren \& Schnitzer 2004), and the time elapsed since issues of gender \& STEM came to the 195 fore (though we concede that for highly specialized or national journals parity may be a greater 
challenge). We argue that Editors must work harder to proactively identify these potential board members - the fact that journals with similar disciplinary foci can have very different representation (e.g., Biological Conservation and Conservation Biology, Biotropica and Journal of Tropical Ecology) suggests increasing the proportion of women on editorial boards can be matter of policy and not pool size.

Attempts by journals to strive for gender parity would greatly increase the number of women afforded the opportunities and benefits that accompany board membership, as well as increase the number of female role models and mentors for early-career scientists and students seeking guidance on scientific publishing. When coupled with initiatives such as double-blind reviewing (Budden et al. 2008) and efforts to explore factors that influence our perceptions of 'merit' (Lortie et al. 2007), editorial board parity could ultimately help reduce the pervasive and insidious "gender productivity puzzle" first identified over thirty years ago (Cole \& Zuckerman 1984). Finally, a more inclusive editorial board might bring unanticipated benefits to the journal itself, including attracting a broader diversity of research topics, contributors, and approaches (Stegmaier, Palmer \& van Assendelft 2011). All of this could greatly increase a journal's impact via shaping both the discipline and the scientific workforce advancing it.

\section{ACKNOWLEDGEMENTS}

We thank R. Primack, R. Eades, C. Lortie, J. Parker, and F. Piper for helpful discussions or feedback on the manuscript and M. Duryea, D. Archer (Interim Deans for Research and Directors of Florida Agricultural Experiment Station), and R. E. Turner (Dean of the College of Agricultural and Life Sciences) for funds to publish in an open-access journal. Data and code used in this paper are available at the Dryad Digital Repository (accession number ---- ----). 


\section{FIGURE LEGENDS}

221 Fig. 1. The proportion of men and women who served as (A) Subject Editors, (B) Associate

222 Editors, and (C) Editors-in-Chief of 10 environmental biology journals from 1985-2013.

224 Fig. 2. Change in the percentage of women on 10 Editorial Boards from 1985-2013. Editorial 225 boards comprise Editors-in-Chief, Associate Editors, and Subject Editors.

Fig. 3. Total number of men and women who served as (A) Editors-in-Chief (B) Associate 228 Editors or (C) Subject Editors of 10 environmental biology journals from 1985-2013. Note that 229 we categorized the Associate Editors of the American Journal of Botany and North American Journal of Fisheries Management as Subject Editors given their responsibilities, and hence are 231 depicted with that category. 
Cho et al., pl 2

\section{REFERENCES}

234 Addis E, and Villa P. 2003. The editorial boards of Italian economics journals: women, gender, 235 and social networking. Feminist Economics 9:75-91.

236 Borsuk R, Budden A, Leimu R, Aarssen L, and Lortie C. 2009. The influence of author gender, 237 national language and number of authors on citation rate in ecology. Open Ecology Journal 2:2523828.

239 Budden AE, Tregenza T, Aarssen LW, Koricheva J, Leimu R, and Lortie CJ. 2008. Double-blind 240 review favours increased representation of female authors. Trends in Ecology \& Evolution 23:42416.

242 Cabanac G. 2012. Shaping the landscape of research in information systems from the perspective

243 of editorial boards: A scientometric study of 77 leading journals. Journal of the American

244 Society for Information Science and Technology 63:977-996.

245 Carroll C. 2014. Can a conservation-oriented scientific society remain relevant in the $21 \mathrm{st}$ 246 century? Conservation Biology 10.1111/cobi.12371.

247 Cole JR, and Zuckerman H. 1984. The productivity puzzle: Persistence and change in patterns of 248 publication of men and women scientists. Advances in Motivation and Achievement 2:217-258.

249 European Commission. 2012. She Figures 2012: statistics and indicators on gender equality in 250 science. Brussels, Belgium: European Commission, Directorate-General for Research and 251 Innovation. 
252 Fox MF. 2008. Institutional transformation and the advancement of women faculty: the case of

253 academic science and engineering. In: Smart JC, ed. Higher education: handbook of theory and

254 research. Amsterdam, The Netherlands: Springer, 73-103.

255 Galley HF, and Colvin LA. 2013. Next on the agenda: gender. British Journal of Anaesthesia 256 111:139-142.

257 Green K. 1998. The gender composition of editorial boards in economics. Royal Economic 258 Society Women's Committee. Available at

259 http://www.res.org.uk/SpringboardWebApp/userfiles/res/file/Womens

260 Committee/Publications/editorialcomposition_Jan1999.pdf (accessed 15 April 2014).

261 Holmgren M, and Schnitzer SA. 2004. Science on the rise in developing countries. Plos Biology

$262 \quad 2: 10-13$.

263 Keiser J, Utzinger J, and Singer BH. 2003. Gender composition of editorial boards of general 264 medical journals. Lancet 362:1336-1336.

265 Lariviere V, Ni CQ, Gingras Y, Cronin B, and Sugimoto CR. 2013. Global gender disparities in 266 science. Nature 504:211-213.

267 Leahey E. 2007. Not by productivity alone: How visibility and specialization contribute to 268 academic earnings. American Sociological Review 72:533-561.

269 Long JS. 2001. From scarcity to visibility: gender differences in the careers of doctoral scientists 270 and engineers. Washington DC, USA: National Academies Press. p 337. 
271 Lortie CJ, Aarssen LW, Budden AE, Koricheva JK, Leimu R, and Tregenza T. 2007. Publication 272 bias and merit in ecology. Oikos 116:1247-1253.

273 Mauleon E, Hillan L, Moreno L, Gomez I, and Bordons M. 2013. Assessing gender balance 274 among journal authors and editorial board members. Scientometrics 95:87-114.

275 Metz I, and Harzing A-W. 2012. An update of gender diversity in editorial boards: a longitudinal 276 study of management journals. Personnel Review 41:283-300.

277 Morton MJ, and Sonnad SS. 2007. Women on professional society and journal editorial boards. 278 Journal of the National Medical Association 99:764-771.

279 Moss-Racusin CA, Dovidio JF, Brescoll VL, Graham MJ, and Handelsman J. 2012. Science 280 faculty's subtle gender biases favor male students. Proceedings of the National Academy of 281 Sciences of the United States of America 109:16474-16479.

282 National Science Foundation. 2003. Gender Differences in the Careers of Academic Scientists 283 and Engineers: A Literature Review (NSF 03-322). Arlington, USA: National Science 284 Foundation, Division of Science Resources Statistics.

285 National Science Foundation. 2004. Gender differences in the careers of academic scientists and 286 engineers (NSF Report 04-323). Arlington, USA: National Science Foundation, Division of 287 Science Resources Statistics. 
288 National Science Foundation. 2012. Doctorate recipients from U.S. universities: 2012 (NSF

289 Report 14-305). Arlington, USA: National Science Foundation, National Center for Science and 290 Engineering Statistics.

291 National Science Foundation. 2014. ADVANCE Program. Available at

292 http://www.nsf.gov/crssprgm/advance/ (accessed 30 July 2014 2014).

293 Parker JN, Allesina S, and Lortie CJ. 2013. Characterizing a scientific elite (B): publication and

294 citation patterns of the most highly cited scientists in environmental science and ecology.

295 Scientometrics 94:469-480.

296 Parker JN, Lortie C, and Allesina S. 2010. Characterizing a scientific elite: the social 297 characteristics of the most highly cited scientists in environmental science and ecology.

298 Scientometrics 85:129-143.

299 Pearson CH, Mullen RW, Thomason WE, and Phillips SB. 2006. Associate editor's role in 300 helping authors and upholding journal standards. Agronomy Journal 98:417-422.

301 Stark BL, Spielmann KA, Shears B, and Ohnersorgen M. 1997. The gender effect on editorial 302 boards and in academia. Bulletin of the Society for American Archeology 15(4). Available at 303 http://www.saa.org/Portals/0/SAA/publications/saabulletin/15-4/SAA6.html (accessed 15 April 304 2014).

305 Stegmaier M, Palmer B, and van Assendelft L. 2011. Getting on the Board: the presence of 306 women in political science journal editorial positions. Political Science \& Politics 44:799-804. 
307 Stocks G, Seales L, Paniagua F, Maehr E, and Bruna EM. 2008. The geographical and

308 institutional distribution of ecological research in the tropics. Biotropica 40:397-404.

309 West JD, Jacquet J, King MM, Correll SJ, and Bergstrom CT. 2013. The role of gender in

310 scholarly authorship. Plos One 8:e66212.

311 Wilkes MS, and Kravitz RL. 1995. Policies, practices, and attitudes of North American medical 312 journal editors. Journal of General Internal Medicine 10:443-450. 


\section{Figure 1}

The proportion of men and women who served as Subject Editors, Associate Editors, and Editors-in-Chief.

Figure 1. Gender Representation on 10 editorial boards in environmental biology. . The proportion of men and women who served as (A) Subject Editors, (B) Associate Editors, and (C) Editors-in-Chief of 10 environmental biology journals from 1985-2013. 


\section{(A) Subject Editors}

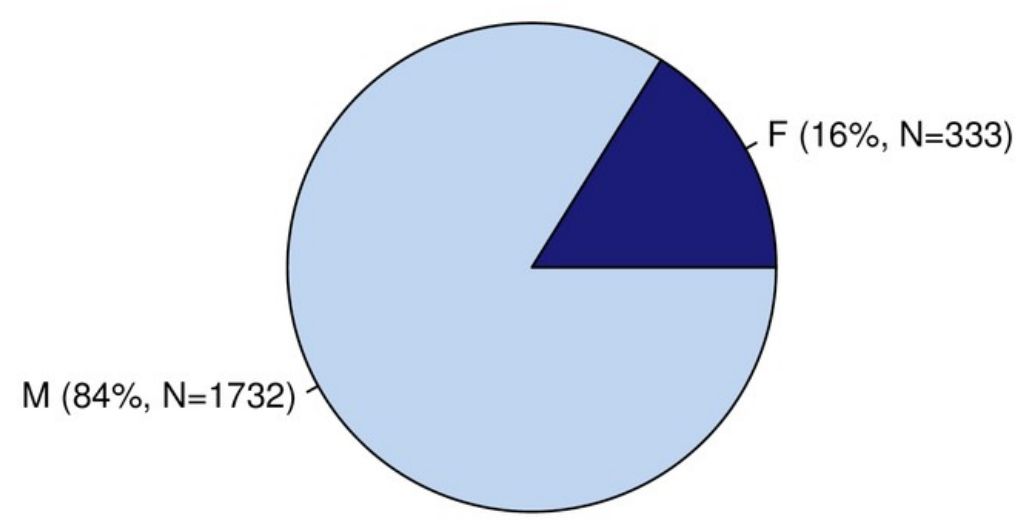

(B) Associate Editors

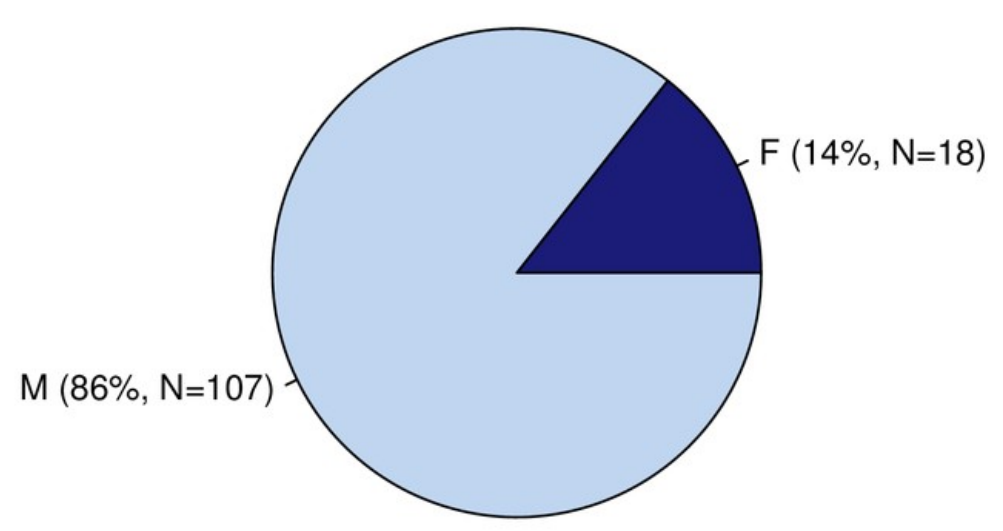

(C) Editors-in-Chief

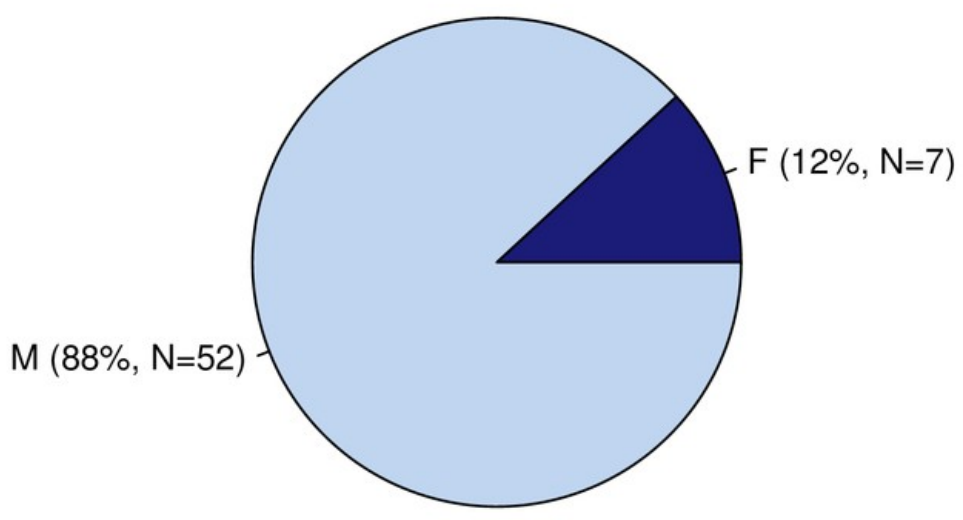




\section{Figure 2}

Percentage of women on 10 editorial boards from 1985-2013.

Figure 2. Change in the percentage of women on 10 Editorial Boards from 1985-2013. Editorial boards comprise Editors-in-Chief, Associate Editors, and Subject Editors.
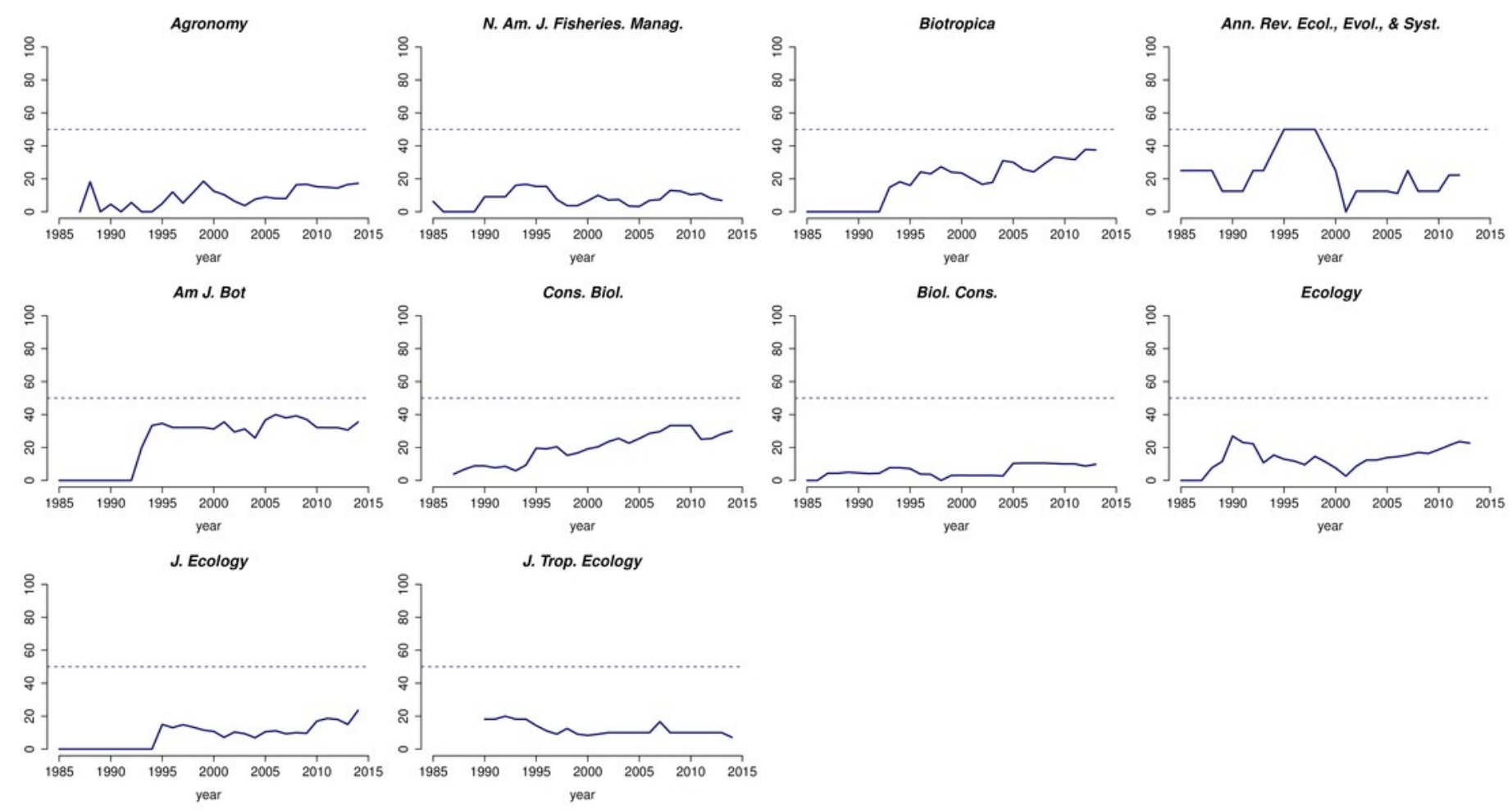


\section{Figure 3}

Number of men and women who served as Editors-in-Chief, Associate Editors, or Subject Editors of 10 environmental biology journals.

Figure 3. Total number of men and women who served as (A) Editors-in-Chief (B) Associate Editors or (C) Subject Editors of 10 environmental biology journals. Data are from from 1985-2013. Note that we categorized the Associate Editors of the American Journal of Botany and North American Journal of Fisheries Management as Subject Editors given their responsibilities, and hence are depicted with that category.[b]
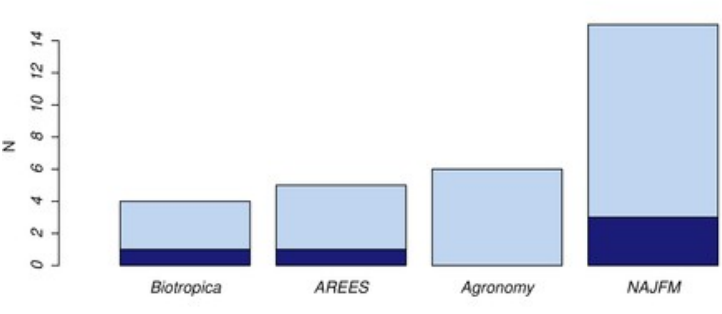

(A) Editors-in-Chief
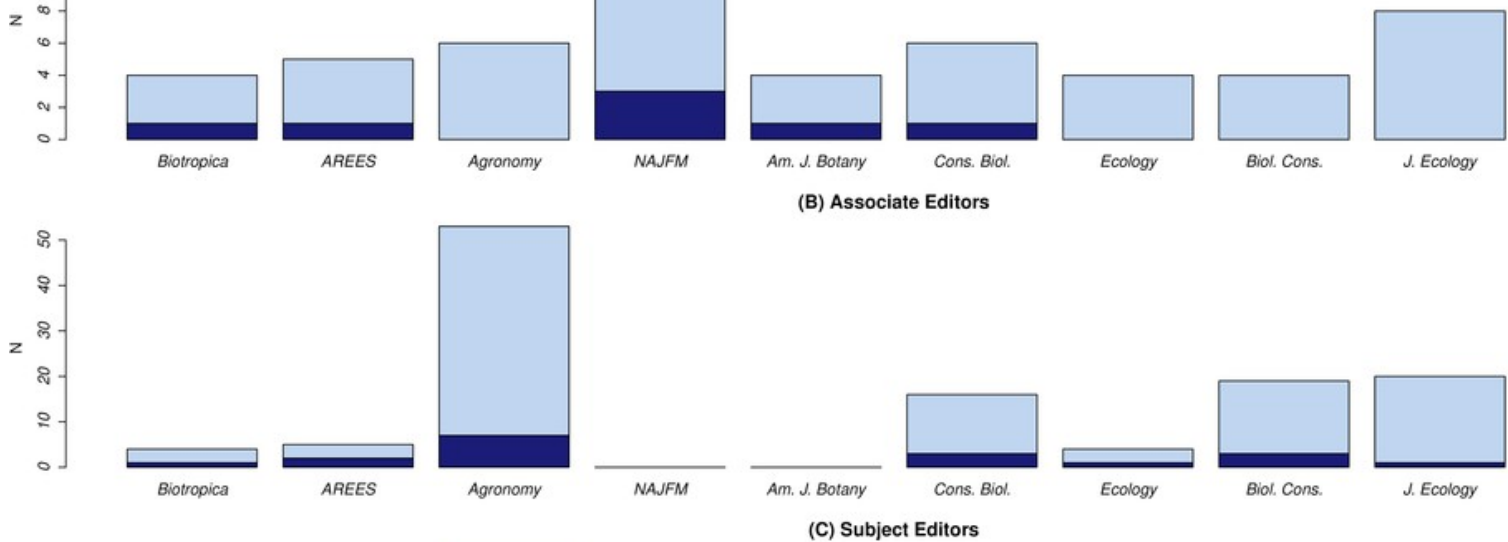

(B) Associate Editors

Biol. Cons.

J. Ecology
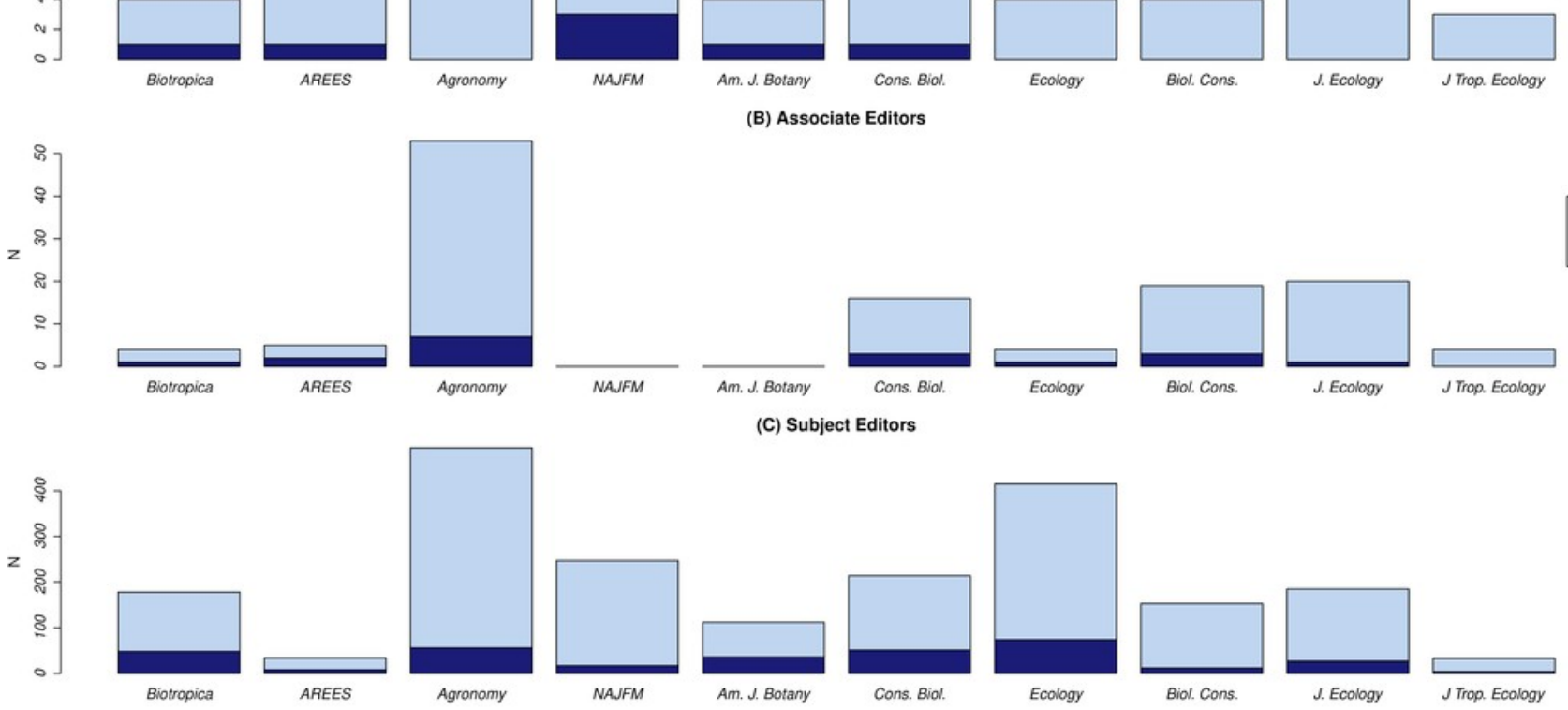

$J$ Trop. Ecology 